Diabetologia $9,108-114(1973)$

(C) by Springer-Verlag 1973

\title{
Morphometric Studies of the Peripheral Glomerular Basement Membrane
}

\section{Topography of the Initial Lesions}

\author{
R. Østerby \\ From the University Institute of Pathology, and the 2nd University Clinic of Internal Medicine, Kommunehospitalet,
} Aarhus, Denmark

Received: August 28, 1972, accepted: November 14, 1972

\begin{abstract}
Summary. Glomerular basement membrane thickness has been estimated by quantitative electron-microscopic study in control subjects and in juvenile diabetics at onset and with short-term diabetes. - The juxta-mesangial part of the basement membrane as well as basement membranes located close to the vascular pole were considered separately and their thickness compared with the remainder of the basement membrane of the same cross section. - It was found that basement membrane, both close to mesangial regions and to the vascular pole, showed greater variation in thickness than the remainder of the glomerular basement membrane. The deviations
\end{abstract}

were, however, small. - The initial thickening occurring in diabetic patients after a few years of the disease was shown to take place as a generalized phenomenon over the entire cross section and did not primarily affect the basement membrane close to mesangial regions or the vascular pole.

Key words: Diabetic glomerulosclerosis, diabetic microangiopaty, glomerular ultrastructure, basement membrane, quantitative stereology, early diabetes, kidney, kidney biopsy.
An evaluation of the initial lesion of the glomerular basement membrane in diabetic patients was made possible by application of quantitative electron-microscopic techniques. The glomerular basement membrane has been shown to be normal at the onset of acute, juvenile diabetes $[12,29]$, and basement membrane thickening is demonstrable after a duration of the disease of about $11 / 2$ years [33].

The aim of the present investigation was to study the localization of the initial thickening of the peripheral glomerular basement membrane in relationship to mesangial regions and to the vascular pole. The topography of the initial basement membrane abnormalities in diabetic glomerulosclerosis has not previously been studied by quantitative electron microscopy.

In light-microscopic studies it has often been stated that diabetic glomerular lesions first appear axially or centrally in the lobules $[18,27]$. However, exact evaluation of the structures involved, i.e. peripheral basement membrane versus mesangial regions, let alone which segments of the peripheral basement membrane, cannot be made at this level of resolution. The authors of one ultrastructural study claimed that thickening of the basement membrane, most markedly in the areas adjacent to mesangial regions, was present as the only abnormality in two cases of prediabetes [4]. This particular part of the peripheral glomerular basement membrane has often been omitted in quantitative studies, both in normal and in diabetic subjects.

Diverging statements have been made as to the site of the primary lesions with respect to the vascular pole, some investigators stating that the lesions first develop at the vascular pole $[3,5,22]$, others that the peripheral part of the glomerular tuft shows the initial lesions $[7,20]$.
The results of the present quantitative study show that the initial thickening of the peripheral glomerular basement membrane is not preferentially located near mesangial regions or in the segment of the glomerulus close to the vascular pole.

\section{Material and Methods}

The patient material studied was identical to that previously reported in detail [33] and will therefore only be briefly described here.

The ages of the patients ranged from 12 to 34 years. Controls consisted of 5 non-diabetic patients without clinical or laboratory signs of kidney disease. For stepwise sectioning of glomeruli (see later in text and in Table 3) two additional non-diabetic cases were studied. They were not included in the remaining part of the study, since in one of the cases the kidney specimen was not an aspiration biopsy, but was obtained as a slice of tissue during operation, and in the other case significant nephrosclerosis was found to be present. Three groups of diabetics were studied. In one group of 7 diabetics a kidney biopsy was obtained on initial admission to hospital because of newly diagnosed, untreated diabetes mellitus, and again after intensive treatment for one month (group $I$, a and $b$ ). A third biopsy was performed in 5 of these patients $1 \frac{1}{2}-$ $2^{1} /$ years later (group II). Biopsy was also performed in 8 juvenile diabetics with a well-established duration of the disease of $3^{1 / 2}-5$ years (group III).

An estimate of glomerular basement membrane thickness was made on the basis of measurements performed on complete glomerular cross sections, produced as photomontages of electron micrographs with a magnification of $13500 \times[33]$. The peripheral basement membrane was defined as the basement membrane of the capillary wall, where the latter is a simple three-layered structure (see Fig. 1), consisting of endothelium, basement membrane and epithelium, i.e. the basement membrane in capillary walls outside mesangial regions. It should be stressed that the term "peripheral" does not designate a relationship 
to the vascular pole or any particular distance from a mesangial region.

The peripheral basement membrane was measured in every loop found in the cross section, starting in each loop tween two sequential levels was roughly estimated by cutting a certain number of sections with the ultramicrotome working continously at a certain feed between two series of thin sections used for electron microscopy.

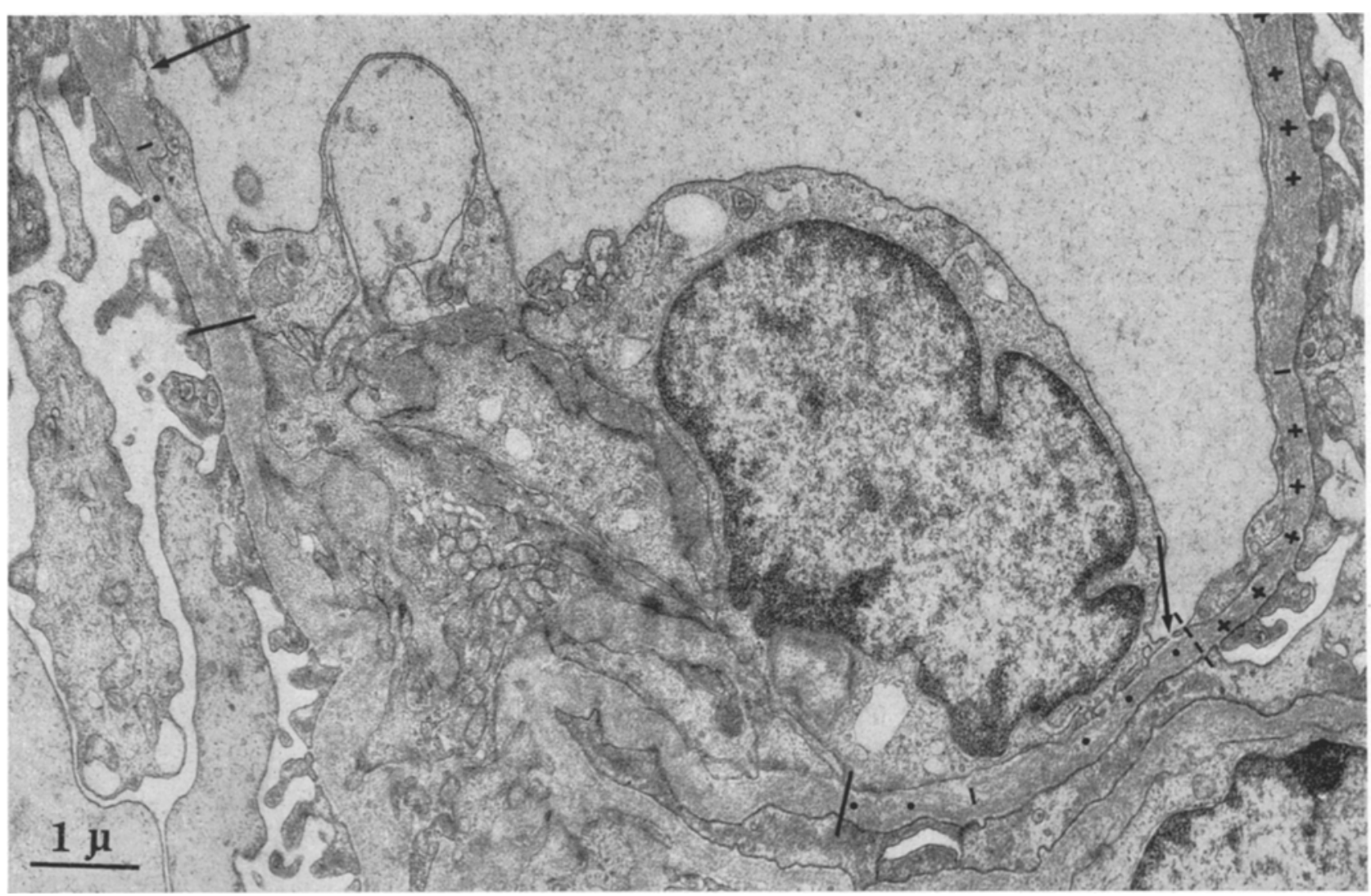

Fig. 1. Electron micrograph of segment of a glomerular capillary tuft. Solid lines: Delineation between mesangial region and the peripheral basement membrane. Dotted lines: The separation between juxta-mesangial and distomesangial parts. Arrows: First endothelial pore after a mesangial region. Dot: measuring points between mesangial region and first endothelial pore. Cross: measuring point after first endothelial pore. I: no measurements taken, because of non-perpendicularity

at the first endothelial pore after a mesangial region (Fig. 1), and omitting sites where non-perpendicular sectioning had occurred [31]. In some cases the first endothelial pore was found at some distance from the mesangial region. In order to make a comparison between measurements obtained close to and far from mosangial regions, additional measurements were taken of the basement membrane situated between the mesangial region and the first pore (in Fig. 1 measurements between the solid line and the arrow).

Measurements from one cross section were divided into two groups, those obtained close to mesangial regions, and those far from it. Separation between the two parts of the basement membrane, in the present study termed "juxta-mesangial" and "disto-mesangial", was arbitrarily placed at $50 \mathrm{~mm}$ from each mesangial region on the micrographs, corresponding to about $3.7 \mu$. These two sets of measurements were then compared, but only in cross sections where at least 200 measurements of the juxta-mesangial basement membrane had been obtained.

Variation in basement membrane thickness in sections with varying localizations with respect to the vascular pole was studied in a few cases, measurements being done on $2-5$ cross sections obtained at various levels within the same glomerulus (Fig. 2 and Table 3 ). The distance be.

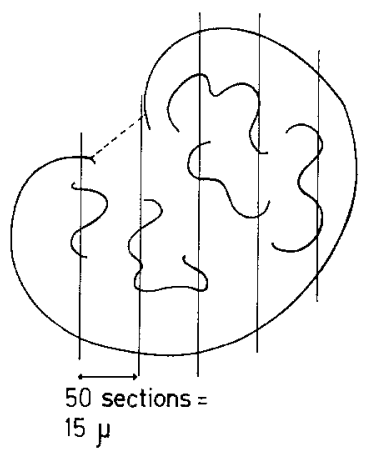

Fig. 2. Sketch illustrating stepwise sectioning in one glomerulus

Obtaining measurements from various levels of one glomerulus was a very time-consuming procedure. In the entire series of controls and patients, a comparison of the measurements obtained close to the vascular pole with those obtained in the opposite part of the glomerulus was therefore obtained by dividing each cross section, which 
contained the vascular pole, as follows: (see Fig. 3). The two points of reflection of Bowman's capsule into the glomerular loops were connected by a line. If the points of reflection were ill-defined, i.e. if there was no acute angle between the basement membrane of Bowman's capsule and the basement membrane of the glomerular tuft, a point mid-way between the two extreme possibilities was selected. From the midpoint of the connecting line, the diameter, a, was drawn so as to approximately separate the glomerular tuft into two equal parts. The

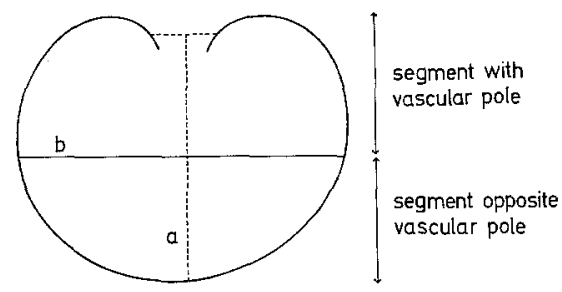

Fig. 3. Glomerular cross section divided by the diameter $b$ into segment containing the vascular pole (indicated at the top), and segment opposite the vascular pole

diameter, $b$, separating the segment containing the vascular pole from the segment opposite the pole, was drawn perpendicular to the diameter, a, through its midpoint. Basement membrane thickness in the pole segment ( $P$ basement membrane) was compared with that in the segment opposite the pole (NP-basement membrane). Only cross sections from which at least 200 measurements could be obtained in each segment were evaluated.

The juxta-mesangial basement membrane was measured in 14 glomeruli from non-diabetics and 58 glomeruli from diabetics (Table 1). The two segments of the glomerular cross section, with and without the vascular pole, were compared in 13 non-diabetic and in 54 diabetie glomeruli (Table 2), and stepwise sectioning was performed in 7 glomeruli (Table 3).

Since the distribution of the actual measurements was markedly right-skewed, a transformation giving a symmetrical distribution was sought. It was found that the transformation to $\sqrt{\frac{1}{T}}$ where $T$ is the measured basement membrane thickness, was optimal in this respect [9], Mean values, $T_{\mathrm{h}}$, calculated from the distributions of $\sqrt{\frac{1}{\mathrm{~T}}}$ were thus the most reliable, unbiased estimates of the unknown means. On comparing mean values, a $5 \%$ level of significance was applied.

\section{Results}

The quantitative study showed that the thickness of the peripheral glomerular basement membrane is normal in juvenile diabetics at onset of disease (group I), and significantly increased in the same patients after 11/2 years' duration. Basement membrane thickness was markedly increased in the diabetics in group III [33].

Owing to the definition of juxta-mesangial basement membrane used the number of measurements obtained here was always less than the number obtained from the disto-mesangial basement membrane. The distribution curves of the measurements from both subdivision of the basement membrane, as well as those for the total number of measurements, were markedly skewed to the right. Comparing the two curves (Fig. 4) it is seen that thin areas of basement membrane occur close to the mesangial regions just as frequently as at a distance from them. The thickness of the juxtamesangial basement membrane, however, shows great variation as it appears from the lower peak and broader right side of the curve.

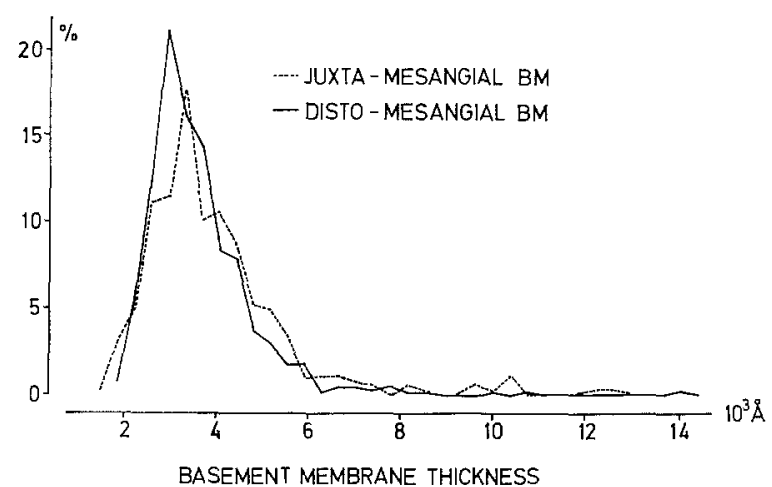

Fig. 4. Distribution of measurements from one glomerular cross section of the juxta-mesangial basement membrane and the disto-mesangial basement membrane

Table 1 shows average values of $T_{h}$ for each of the two segments of the peripheral basement membrane in the groups of patients. In all of the groups the mean value for the juxta-mesangial basement membrane is higher than for the disto-mesangial basement membrane. The difference, however, is small in all groups. There appears to be no difference between the controls and newly diagnosed diabetics for either of the separate segments of the basement membrane, whereas there is a significant increase in thickness of both the juxtamesangial basement membrane and the disto-mesangial basement membrane $(2 p<0.001)$ in the diabetics in group III. A paired comparison between results obtained in 5 of the diabetics at onset and in the same patients after $1 \frac{1}{2}-21 / 2$ years' duration shows a significant increase in thickness of both segments of the basement membrane $(2 p<0.05$ and $2 p<0.025$ for juxta-mesangial and disto-mesangial, respectively).

The difference between $\mathrm{T}_{\mathrm{h}}$ for the juxta-mesangial and disto-mesangial basement membrane was positive for most of the glomerular cross sections studied (92\%) and there was a tendency towards higher values in group D IIT. Calculating this difference in percentage of the mean value, $\mathrm{T}_{\mathrm{h}}$, for the total number of measurements gave results as shown in Table 1 . No difference was found between controls and recently diagnosed diabetics, and no correlation with duration of diabetes is found. Thus, the conclusions to be drawn are, firstly that the juxta-mesangial basement membrane is normal at the onset of diabetes, and secondly, that the initial thickening of the basement membrane, which takes place during the first years of diabetes, is not located preferentially close to the mesangial regions. 
Basement membrane measurements from the two glomerular segments, one containing the vascular pole, and one opposite the pole, were compared in the same manner. Distribution curves from the two segments of one glomerulus appear in Fig. 5. It was usually found, as illustrated in the figure, that the curve representing P-basement membrane was a little displaced to the right, and basement membrane thickness showed the controls, and there was no correlation with the duration of diabetes.

The results obtained on stepwise sectioning of glomeruli are shown in Table 3 and Fig. 6 . The figure shows a clear tendency towards thinner basement membranes with increasing distance between the level of the cross section and the vaseular pole. Applying Page's test [24], modified with regard to the varying

Table 1. Basement membrane thickness for the juxta-mesangial and disto-mesangial segments, and intraglomerular difference between the two segments

\begin{tabular}{llll}
\hline Group & $\begin{array}{l}\text { juxta-mesangial } \\
\text { basement } \\
\text { membrane } \\
\mathrm{T}_{\mathrm{h}}, \AA \pm \mathrm{SD}\end{array}$ & $\begin{array}{l}\text { disto-mesangial } \\
\text { basement } \\
\text { membrane } \\
\mathrm{T}_{\mathrm{h}}, \AA \pm \mathrm{SD}\end{array}$ & $\begin{array}{l}\text { intra-glomerular } \\
\text { difference between } \\
\text { juxta-mesangial and } \\
\text { disto-mesangial } \\
\text { basement membrane } \\
\%^{\mathrm{a}}\end{array}$ \\
\hline ND & $3150 \pm 165$ & $3070 \pm 316$ & $\mathbf{5 . 0 \pm 4 . 8}$ \\
D Ia & $3380 \pm 304$ & $3130 \pm \mathbf{3 5 4}$ & $8.3 \pm 3.8$ \\
D Ib & $3250 \pm 141$ & $3040 \pm 238$ & $7.0 \pm 4.2$ \\
D II & $3530 \pm 356$ & $3330 \pm \mathbf{2 6 5}$ & $6.1 \pm 2.3$ \\
D III & $4420^{\mathrm{b}} \pm 436$ & $\mathbf{4 1 4 0} \pm 374$ & $6.4 \pm 2.4$ \\
\hline
\end{tabular}

a expressed as percentage of $T_{h}$ for the total number of measurements.

$\mathrm{b}$ significantly different from ND $(2 p<0.001)$.

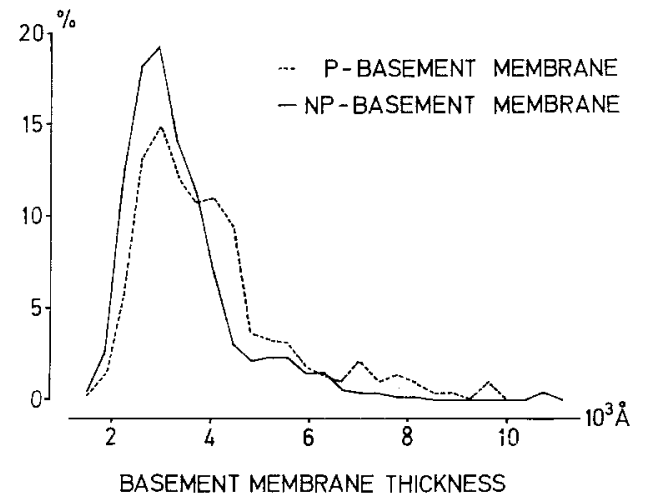

Fig. 5. Distribution of basement membrane measurements from one glomerular cross section of the P-basement membrane and the NP-basement membrane

greater variation in this segment. The results presented in Table 2 show that P-basement membrane as well as NP-basement membrane are normal at the onset of diabetes. On paired comparison basement membrane thickening was demonstrable in both segments after $11 / 2$ years' duration of diabetes $(2 \mathrm{p}<0.01(\mathrm{P})$, and $2 \mathrm{p}<0.05(\mathrm{NP}))$. The difference in basement membrane thickness between controls and diabetics in group III is highly significant for both individual segments $(2 \mathrm{p}<0.001)$.

The intra-glomerular difference between $T_{h}$ for $P$ and NP-basement membrane was positive in the majority of the glomerular cross sections (91\%) and a tendency towards higher values obtained in group D III. Average values for this difference in the 3 groups of patients expressed as \% of $\mathbf{T}_{\mathrm{h}}$, appear in Table 2 . None of the groups of diabetics differ significantly from

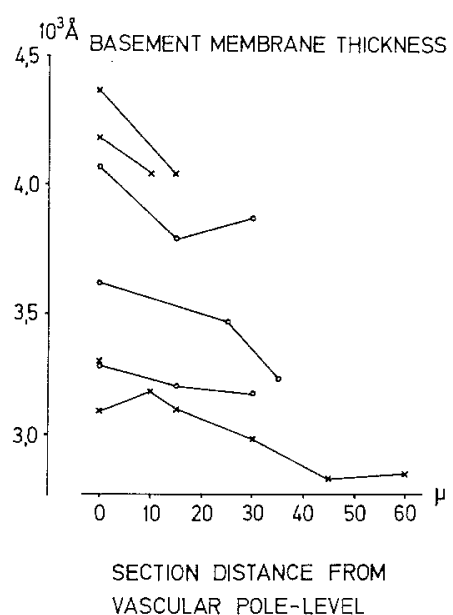

Fig. 6. Plot of $T_{h}$ against distance between level of cross section and vascular pole. Results obtained from stepwise sectioning of one glomerulus are connected with lines

number of observations in the individuals [8], the tendency was shown to be highly significant $(2 p<$ $0.002)$.

\section{Discussion}

A clear distinction between the peripheral basement membrane, as defined in the present paper, and the mesangial basement membrane-like material is relevant for several reasons [30]. Only the peripheral basement membrane is, with regard to morphology, a true membrane, whereas the basement membrane-like material of mesangial regions is a sponge-like meshwork. Therefore, for a quantitative evaluation the two 
parts have to be handled in different ways. The separation has, of course, to be made arbitrarily, since all of the basement membrane material of the glomerulus is in direct continuity. Separation, however, can be made without too much difficulty [34]. The mesangial basement membrane-like material is not increasing thickness occurring when approaching a mesangial region [21]. When, however, measurements are only made at places where both endothelial and epithelial cell membranes are distinct, the true basement membrane thickness at a given point is obtained [31]. If greater tortuousity was found at this region, it

Table 2. Basement membrane thickness for the segment with the vascular pole $(P)$, and segment opposite the pole (NP), and intraglomerular difference between the two segments

\begin{tabular}{llll}
\hline Group & $\begin{array}{l}\text { P-basement } \\
\text { membrane } \\
\mathrm{T}_{\mathrm{h}}, \AA \pm \mathrm{SD}\end{array}$ & $\begin{array}{l}\text { NP-basement } \\
\text { membrane } \\
\mathrm{T}_{\mathrm{h}}, \AA \pm \mathrm{SD}\end{array}$ & $\begin{array}{l}\text { Intra-glomerular } \\
\text { difference between } \\
\text { P-and NP- } \\
\text { basement membrane, } \\
\% \mathrm{a}\end{array}$ \\
\hline ND & $3150 \pm 137$ & $2930 \pm 180$ & $7.2 \pm 4.3$ \\
D Ia & $3300 \pm 350$ & $3080 \pm 293$ & $6.7 \pm \mathbf{2 . 7}$ \\
D Ib & $3180 \pm 253$ & $2990 \pm 233$ & $5.9 \pm 2.2$ \\
D II & $3490 \pm 384$ & $3320 \pm 342$ & $7.0 \pm \mathbf{3 . 7}$ \\
D III & $4630^{\mathrm{b}} \pm 360$ & $4040^{\mathrm{b}} \pm \mathbf{3 5 0}$ & $\mathbf{7 . 0 \pm 2 . 9}$ \\
\hline
\end{tabular}

a expressed as percentage of $\mathrm{T}_{\mathrm{h}}$ for the total number of measurements.

b significantly different from ND $(2 p<0.001)$.

Table 3. Mean basement membrane thickness, $T_{\mathrm{h}}$, obtained at different levels within individual glomeruli

\begin{tabular}{|c|c|c|c|c|c|}
\hline $\begin{array}{l}\text { Patient } \\
\text { group }\end{array}$ & $\begin{array}{l}\text { case } \\
\text { numbers }\end{array}$ & $\begin{array}{l}\text { number of } \\
\text { measurements } \\
\text { per cross } \\
\text { section }\end{array}$ & $\begin{array}{l} \pm \text { vascular } \\
\text { pole on the } \\
\text { the section }\end{array}$ & $\begin{array}{l}\text { distance } \\
\text { from } \\
\text { foregoing } \\
\text { section, } \mu\end{array}$ & $\begin{array}{l}\text { basement } \\
\text { membrane } \\
\text { thickness } \\
\mathrm{T}_{\mathrm{h}}, \AA\end{array}$ \\
\hline $\mathrm{ND}$ & 17 & $\begin{array}{r}783 \\
1858 \\
1987 \\
373\end{array}$ & $\begin{array}{l}+ \\
+ \\
+\end{array}$ & $\begin{array}{l}15 \\
15 \\
15\end{array}$ & $\begin{array}{l}3130 \\
3300 \\
3220 \\
3190\end{array}$ \\
\hline $\mathrm{ND}$ & 21 & $\begin{array}{l}1064 \\
1171 \\
1631\end{array}$ & $\begin{array}{l}+ \\
- \\
-\end{array}$ & $\begin{array}{l}25 \\
10\end{array}$ & $\begin{array}{l}3620 \\
3470 \\
3250\end{array}$ \\
\hline $\mathrm{ND}$ & 22 & $\begin{array}{r}841 \\
1287 \\
612\end{array}$ & $\begin{array}{l}(+)^{a} \\
-\end{array}$ & $\begin{array}{l}15 \\
15\end{array}$ & $\begin{array}{l}4070 \\
3790 \\
3870\end{array}$ \\
\hline D group I & 3 & $\begin{array}{r}560 \\
1336 \\
1717 \\
1677 \\
803\end{array}$ & $\begin{array}{l}\frac{+}{-} \\
- \\
-\end{array}$ & $\begin{array}{l}15 \\
15 \\
15 \\
15\end{array}$ & $\begin{array}{l}3310 \\
3130 \\
3020 \\
2860 \\
2880\end{array}$ \\
\hline D group I & 4 & $\begin{array}{r}1089 \\
713\end{array}$ & + & 10 & $\begin{array}{l}3130 \\
3200\end{array}$ \\
\hline D group III & 12 & $\begin{array}{l}715 \\
859 \\
962\end{array}$ & $\begin{array}{l}+ \\
+ \\
-\end{array}$ & $\begin{array}{l}15 \\
15\end{array}$ & $\begin{array}{l}4160 \\
4360 \\
4040\end{array}$ \\
\hline D group III & 15 & $\begin{array}{l}1496 \\
1771\end{array}$ & \pm & 10 & $\begin{array}{l}4190 \\
4040\end{array}$ \\
\hline
\end{tabular}

a immediately past vascular pole. Arteriole was adjacent to the outside of Bowman's capsule.

included in the present measurements. The juxtamesangial part of the peripheral basement membrane has often been neglected in quantitative studies $[10$, $13,14,15,16,21,28$ ]. The reasons given for omitting this part of the basement membrane have been the great irregularity or tortuousity $[10,13,14,16]$, or the would only mean that a smaller number of measurements per unit length could be obtained. Irregularity in thickness is also found in the disto-mesangial part of the basement membrane, and neither this quality nor tortuousity are good criteria for exclusion from measurements. Since the thickness of the basement 
membrane is the unknown investigated, it seems dangerous to exclude some parts because of increase in thickness. In none of the cited papers has a clear definition been given of the part of the basement membrane, i.e. how far from mesangial regions, on which measurements were performed.

The results of the present study showed that measurements obtained from the juxta-mesangial basement membrane generally showed greater variation than those from the disto-mesangial basement membrane. The average difference between the two segments was positive in all groups of patients. This difference, however, was small, being a few hundred $\AA$ in the various groups of patients, and in occasional glomeruli it was, in fact, negative. Discrepancies in normal basement membrane thickness in various studies $[12,13,14,23,33]$ cannot therefore be attribut. ed to omitting or including this part of the basement membrane, but are more likely due to the methods employed or the patient material used.

Quantitative estimation of the juxta-mesangial part of the basement membrane in diabetic patients showed that this particular segment is also normal at the onset of juvenile diabetes. This finding is in contradistinction to the report of basement membrane thickening at this localization in prediabetes [4]. However, the latter study was not based on quantitation. The great variability normally observed in this region makes conclusions based on mere impression quite uncertain.

The finding in the present study of thickening of both the juxta-mesangial and disto-mesangial basement membrane in group D II (duration of diabetes $1 \frac{1}{2}-21 / 2$ years) contradicts Kimmelstiel's suggestion that thickening of the peripheral basement membrane comes about as an extension of a primary involvement of the basement membrane-like material in mesangial regions [16].

In no previous studies have basement membrane measurements been correlated to the localization of the section with respect to the vascular pole. It was found in the present investigation that the peripheral basement membrane shows greater thickness and variation when the loops close to the vascular pole are considered. The question could therefore be raised, whether results of basement membrane measurements depend on the localization of the plane of section through a glomerulus. However, the systematic change in basement membrane measurements observed in the present study on stepwise sectioning was only slight. Therefore, if only cross sections of a certain, not too small width are included, it seems justified to accept one cross section as representative for the glomerulus in question. In the study of basement membrane thickness in patients with early diabetes only those cross sections were considered in which at least 400 measurements could be obtained. The material comprised 80 cross sections containing the vascular pole, and 19 which did not. On the basis of the present study of intra-glomerular variation it can be concluded that the presence of a small number of cross sections not containing the vascular pole, would not be able to influence the results.

An effort to localize the initial thickening of the peripheral basement membrane in diabetic glomerulopathy has not previously been attempted on the basis of a quantitative electron microscopic study. In the present investigation it was found that the relationship between the juxta-mesangial and the disto-mesangial basement membrane was the same in controls, in juvenile diabeties at onset and in diabetics with a measurable degree of basement membrane thickening. It was also shown that the segment of the glomerulus opposite the vascular pole is involved to the same extent as the segment containing the vascular pole. This is in contradistinction to the impression gained from light-microscopic studies, in which axial and hilar areas have been stated to be primarily involved.

It must be stressed that the present report deals exclusively with the peripheral basement membrane. With light microscopy a clear distinction between mesangial regions and peripheral basement membrane cannot be made. A quantitative electron microscopic study of mesangial regions has been performed in the same patient material. The results showed that mesangial regions are not involved prior to the peripheral basement membrane, and that the initial increase in basement membrane-like material in mesangial regions does not occur preferentially close to the vascular pole [33].

The mechanism responsible for increase in basement membrane thickness in diabetes mellitus is unknown. One theoretical possibility is a change in the normal basement membrane metabolism, affecting either the synthesis or the break-down of the basement membrane $[6,11,19,26]$, or both. It has been shown recently that diabetic basement membranes differ chemically from normal basement membrane $[2,25]$, a finding which might indicate a change in synthesis. Glomerular epithelial cells appear to be involved in the synthesis of basement membranes [1, 17, 32]. If a change in synthesis takes place in diabetic patients it would probably affect all parts of the basement membrane at the same time. Obviously, no conclusion can be drawn regarding basement membrane metabolism from the results of the present study. However, it might be stated that they are in accordance with the occurrance of a change in basement membrane metabolism taking place as a generalized phenomenon throughout the glomerulus.

Acknowledgements. I am indebted to Dr. G. Gregersen for doing the kidney biopsies, and to Drs. B. Møller and H. Skjoldborg, who supplied some of the biopsy material. My thanks are due also to Dr. H.J. Gundersen for statistical analysis of the data.

Supported by grants from: Statens laegevidenskabelige Forskningsråd, Michaelsen fonden, Novo fonden, Rask-Ørsted fonden, and Nordisk Insulinfond. 


\section{References}

1. Andres, G.A., Morgan, C., Hsu, K.C., Rifkind, R.A., Seegal, B.S.: Electron microscopic studies of experimental nephritis with ferritin-conjugated antibody. J. exp. Med. 115, 929-935 (1962).

2. Beisswenger, P.J., Spiro, R.G.: Human glomerular basement membrane: Chemical alteration in diabetes mellitus. Science 168, 596-598 (1970).

3. Bergstrand, A.F., Bucht, H.: Electron microscopic studies of the diabetic kidney. In: Siperstein, M.D., Colwell, A.R., Meyer, K.: Blood vessel involvement in diabetes mellitus, p. 65-72. Washington D.C.: American Institute of Biological Sciences 1964.

4. Camerini-Dávalos, R.A., Rees, S.B., Caulfield, J.B., Lozano-Castaneda, O., Marble, A.: Vascular changes in prediabetes. In: Siperstein, M.D., Colwell, A.R., Meyer, K. : Small blood vessel involvement in diabetes mellitus, p. 107-112. Washington D.C.: American Institute of Biological Sciences 1964.

5. Farquhar, M.G., Hopper, J., Jr., Moon, H.D.: Diabetic glomerulosclerosis: Electron and light microscopic studies. Amer. J. Path. 35, $721-754$ (1959).

6. Farquhar, M.G.: Discussion, In; Siperstein, M.D., Colwell, A.R., Meyer, K. : Small blood vessel involvement in diabetes mellitus, p. 73. Washington D.C.: American Institute of biological Sciences 1964.

7. Gellman, D.D., Pirani, C.L., Soothill, J.F., Muehreke, R.C., Kark, R.M.: Diabetic nephropathy: A clinical and pathologic study based on renal biopsies. Medicine $38,321-367(1959)$.

8. Gundersen, H.J.G.: Personal communication.

9. Gundersen, H.J.G., Østerby, R.: Statistical analysis of transformations leading to normal distribution of measurements of the peripheral glomerular basement membrane. J. Microscopy, in press.

10. Ireland, J.T., Patnaik, B.K., Duncan, L.J.P.: Glomerular ultrastructure in secondary diabetics and normal subjects. Diabetes 16, 628-635 (1967).

11. Ireland, J.T., Patnaik, B.K., Duncan, L.J.P.: Effect of pituitary ablation on the renal arteriolar and glomerular lesions in diabetes. Diabetes 16, 636-642 (1967).

12. Ireland, J.T.: Diagnostic criteria in the assessment of glomerular capillary basement membrane lesions in newly diagnosed ljuvenile diabeties. In: CameriniDávalos, R.A., Cole, H.S.: Early diabetes, p. 273278. New York: Academic Press 1970.

13. Jørgensen, F.: The ultrastructure of the normal human glomerulus. Copenhagen: Munksgaard 1966.

14. Jørgensen, F., Weis Bentzon, M.: The ultrastructure of the normal human glomerulus. Thickness of glomerular basement membrane. Lab. Invest. 18, 42-48 (1968).

15. Kimmelstiel, P., Osawa, G., Beres, J.: Glomerular basement membrane in diabetics. Amer. J. clin. Pathol. 45, $21-31$ (1966).

16. Kimmelstiel, P.: Diabetic Nephropathy. In: Mostofi, F.K., Smith, D.E.: The kidney, p. 226-252. Baltimore: Williams and Wilkins Co. 1966.

17. Kurtz, S. M., Feldman, J.D.: Experimental studies on the formation of the glomerular basement membrane. J. Ultrastruct. Res. 6, 19-27 (1962).

18. Lannigan, R., Blainey, J.D., Brewer, D. B.: Electron microscopy of the diffuse glomerular lesion in diabetes mellitus with special reference to early changes. J. Path. Bact. 88, 255-261 (1964).

19. Lazarow, A., Speidel, E.: The chemical composition of the glomerular basement membrane and its rela- tionship to the production of diabetic complications. In: Siperstein, M.D., Colwell, A.R., Meyer, K.: Small blood vessel involvement in diabetes mellitus, p. $127-$ 150. Washington D. C.: American Institute of Biological Sciences 1964.

20. LeCompte, Ph.M.: Glomerular lesions in diabetes: Light microscopy and histochemistry. In: Siperstein, M.D., Colwell, A.R., Meyer, K.: Small blood vessel involvement in diabetes mellitus, p. $1-6$. Washington D.C.: American Institute of Biological Sciences 1964.

21. MacDonald, M.K., Treland, J.T.: The glomerular lesion in idiopathic and secondary diabetes. In: Ciba Foundation Colloquia on Endocrinology, vol. 15: The aetiology of diabetes mellitus and its complications. Cameron, M.P., O'Connor, M. (eds.), p. 301-314. London: J. \& A. Churchill, Ltd. 1964.

22. Ormos, J., Solbach, H.-G.: Beitrag zur Morphologie der Niere bei diabetes mellitus. Frankf. Zeitschr. Path. 72, 379-418 (1963).

23. Osawa, G., Kimmelstiel, P., Seiling, V.: Thickness of glomerular basement membranes. Amer. J. clin. Path. 45, 7-20 (1966).

24. Page, E.B.: Ordered hypothesis for multiple treatments: A significance test for linear ranks. J. Amer. Stat. Ass. 58, 216-230 (1963).

25. Spiro, R.G.: Chemistry and metabolism of the basement membrane. In: Ellenberg, M., Rifkin, H.: Diabetes mellitus: Theory and Practice, p. $210-229$. New York: McGraw-Hill 1970.

26. Spiro, R.G., Spiro, M.J.: Studies on the biosynthesis of the hydroxylysine-linked disaccharide unit of basement membranes and collagens. III. Tissue and subcellular distribution of glycosyltransferases and the effect of various conditions on the enzyme levels. J. Biol. Chem. 246, 4919-4925 (1971).

27. Thomsen, A.Chr.: The kidney in diabetes mellitus. Copenhagen: Munksgaard 1965.

28. Urizar, R.E., Schwartz, A., Top, F., Jr., Vernier, R. L.: The nephrotic syndrome in children with diabetes mellitus of recent onset. Report of five cases. New Engl. J. Med. 281, 173-181 (1969).

29. Østerby Hansen, R.: A quantitative estimate of the peripheral glomerular basement membrane in recent juvenile diabetes. Diabetologia 1, 97-100 (1965).

30. Østerby, R., Lundbaek, K.: The basement membrane morphology in diabetes mellitus. In: Ellenberg, M., Rifkin, H.: Diabetes mellitus: Theory and Practice, p. 178-209. New York: McGraw-Hill 1970.

31. Osterby, R.: Quantitative electron microscopy of the glomerular basement membrane. A methodologic study. Lab. Invest. 25, 15-24 (1971).

32. Østerby, R., Ledet, T., Lundbaek, K., Steen Olsen, T., Ørskov, H.: On the mechanism of basement membrane thickening in alloxan diabetic rats. J. Ultrastruct. Res. 36, 544-546 (1971), (abstract).

33. Østerby, R.: Morphometric studies of the peripheral glomerular basement membrane in early juvenile diabetes. I. Development of initial basement membrane thickening. Diabetologia 8, 84-92 (1972).

34. Østerby, R.: A quantitative electron microscopic study of mesangial regions in glomeruli from patients with short-term, juvenile diabetes mellitus. Submitted for publication.

Ruth Østerby, M.D.
Dept. of Pathology
Kommunehospitalet
DK-8000-Aarhus C
Denmark

Ruth Østerby, M.D.

Kommunehospitalet

Denmark 